\title{
Infantile Colic: Incidence and Effectiveness of Conventional Therapy
}

\author{
Laila $\mathrm{SZ}^{1}$, Beauty $\mathrm{AA}^{2}$, Hasan $\mathrm{MM}^{3}$, Khan $\mathrm{MMR}^{4}$
}

\begin{abstract}
Introduction: Infantile colic is defined as excessive crying for more than three hours a day at least three days a week for one week or more in an otherwise healthy baby. It is most frequently observed in neonates and infants aged two weeks to four months.
\end{abstract}

Objective: To assess the incidence of infantile colic and effectiveness of conventional therapy.

Materials and Methods: This was a prospective cross sectional study of 50 cases carried out in Paediatric out patient department in Combined Military Hospital (CMH) Ghatail during the period of September 2010 to August 2012. Data recorded including demographics, clinical presentations, management and the outcome of therapy.

Results: Out of the total 50 patients, 24(48\%) were male and 26(52\%) were female. Male:Female=1:1.08. Babies delivered vaginally suffered more $32(64 \%)$, full term delevered babies $33(66 \%)$ suffered more than that of gestational age group $<37 \mathrm{wk}$. Non-exclusive Breastfed (Formula fed, combination of breastfed and formula fed) babies having more incidence of colic $31(62 \%)$. Maximum patients $26(52 \%)$ had history of cry 4-5 hours per day. Motion (Rocking, bouncing, walking etc) $18(36 \%)$, change of diet $14(28 \%)$ were considerable satisfactory treatments.

Conclusion: Since it is a self limiting condition, conventional therapy should be tried for instant relief.

Key-words: Infantile colic, Incidence, Effectiveness of therapy.

\section{Introduction}

An infant is not supposed to be quiet even if completely healthy. Crying is one of the few ways in which an infant can express his or her emotions and one of the most powerful means of communication ${ }^{1}$.
Infantile colic is a condition in which an otherwise healthy baby cries or screams frequently and for extended periods, without any discernible reason. The condition typically appears within the first month of life and often disappears, often very suddenly, before the baby is three to four months old, but can last up to 12 months of life ${ }^{2}$.

Persistent infant crying is much more than a parenting nuisance. Crying and the exhaustion associated with it can trigger serious problems, such as relationship stress $^{3}$, breastfeeding failure ${ }^{4}$, shaken baby syndrome (also known as abusive head trauma- the leading cause of child abuse fatalities) ${ }^{5}$, postpartum depression (affecting $10-15 \%$ of new mothers and many new dads $)^{6}$, excess visits to the doctor/emergency room (1 in 6 children are brought to the doctor/emergency rooms for evaluation of persistent crying) $)^{7}$, unnecessary treatment for acid reflux $^{8,9}$ and maternal smoking ${ }^{10}$. Crying and exhaustion may also contribute to Sudden Infant Death Syndrome (SIDS) and suffocation (from agitated babies flipping onto their stomachs, concerned parents placing fussy babies on the stomach to sleep, tired parents falling asleep with their baby in unsafe places- like couches or beds with bulky covers) ${ }^{11}$, infant obesity ${ }^{12}$, maternal obesity $^{13}$ and even automobile accidents ${ }^{14}$.

This study in addition to its 50 patients undertook a systematic review of all conventional therapies for infantile colic. The goal of this study was to present the findings in a coherent and systematic way so that practitioners can evaluate each potential therapy in terms of its proven benefits and risks as well as the rigor with which it has been evaluated.

\section{Materials and Methods}

This was a prospective cross sectional study and was carried out in Paediatric out patient department in Combined Military Hospital (CMH) Ghatail during the period of September 2010 to August 2012.

1. Maj Syeda Zeenat Laila, MBBS, DCH, FCPS, Classified Specialist in Paediatrics, OKP-5, Kuwait 2. Col Anjuman Ara Beauty, MBBS, DCH, FCPS, Classified Specialist in Paediatrics, CMH, Dhaka 3. Lt Col Md Mahboob Hasan, MBBS, FCPS, Diploma (Hepatobiliary Surgery), Classified Specialist in surgery \& Hepatobiliary Surgeon, CMH, Dhaka 4. Lt Col Md Mizanur Rahman Khan, MBBS, MPH, FCGP, FRSH, CMH, Dhaka. 
A total 50 patients diagnosed as infantile colic were studied. Colic was defined according to modified Wessel's criteria as episodes of fussy crying that lasted 3 or more hours a day and episodes that lasted for 3 or more days in the week before enrollment in the study. Upon agreement to enter into the study, a detailed history was taken from the patient's attendent. Data recorded including demographics, clinical presentations, laboratory investigation reports and management. All the patients were followed up regularly in Paediatric out patient department.

\section{Results}

The youngest patient of this series was 3 weeks of age. Male 24(48\%) and Female 26(52\%); Male:Female $=1: 1.08$. Maximum patients $(48 \%)$ fall in $1-3$ months age group (Table-I).

Table-I: Age and Sex distribution $(n=50)$

\begin{tabular}{|c|c|c|c|c|c|}
\hline Age(Months) & Male & Female & Total & $\mathbf{\%}$ & \multirow{2}{*}{ M:F } \\
\hline$<1$ & 04 & 05 & 09 & 18 & \\
\cline { 1 - 5 } $1-3$ & 06 & 05 & 11 & 22 & \multirow{2}{*}{$1: 1.08$} \\
\hline $3-6$ & 08 & 10 & 18 & 36 & \\
\hline $6-9$ & 02 & 04 & 06 & 12 & \\
\hline $9-12$ & 04 & 02 & 06 & 12 & \\
\hline Total & $\mathbf{2 4}$ & $\mathbf{2 6}$ & $\mathbf{5 0}$ & $\mathbf{1 0 0}$ & \\
\hline
\end{tabular}

Babies delevered vaginally suffered more 32(64\%), full term delevered babies $33(66 \%)$ suffered more than that of gestational age group $<37 \mathrm{wk}$. Incidence of colic was less in low birth weight babies $12(24 \%)$. Dietory history shows Non-exclusive Breastfed (Formula fed, combination of breastfed and formula fed) babies having more incidence of colic 31(62\%)(Table-II).

Table-II: Comparison of potential predictors of infantile colic $(n=50)$

\begin{tabular}{|c|c|c|c|}
\hline \multicolumn{2}{|l|}{ Factors } & Patients (n) & $\%$ \\
\hline \multirow{2}{*}{$\begin{array}{l}\text { Mode of } \\
\text { Delivery }\end{array}$} & Vaginal & 32 & 64 \\
\hline & Cesarean & 18 & 36 \\
\hline \multirow{3}{*}{$\begin{array}{l}\text { Mother's } \\
\text { Age }\end{array}$} & ? 19 years & 11 & 22 \\
\hline & 20-35 years & 25 & 50 \\
\hline & $>35$ years & 14 & 28 \\
\hline \multirow{2}{*}{$\begin{array}{l}\text { Gestational } \\
\text { age at birth }\end{array}$} & $\geq 37 \mathrm{wk}$ & 33 & 66 \\
\hline & $<37 \mathrm{wk}$ & 17 & 34 \\
\hline \multirow{2}{*}{$\begin{array}{l}\text { Birth } \\
\text { Weight }\end{array}$} & $\geq 2500 \mathrm{~g}$ & 38 & 76 \\
\hline & $<2500 \mathrm{~g}$ & 12 & 24 \\
\hline \multirow{2}{*}{$\begin{array}{l}\text { Birth } \\
\text { Order }\end{array}$} & First born & 34 & 68 \\
\hline & Later born & 16 & 32 \\
\hline \multirow{2}{*}{$\begin{array}{l}\text { Mode of } \\
\text { Feeding }\end{array}$} & Exclusive breastfed & 19 & 38 \\
\hline & *Non-exclusive breastfed & 31 & 62 \\
\hline
\end{tabular}

Maximum patients $29(58 \%)$ had history of cry 3-4 hours per day (Table-III).

Table-III: Duration of crying $(n=50)$

\begin{tabular}{|c|c|c|}
\hline Duration of crying & Number of patients & (\%) \\
\hline $3-4 \mathrm{~h} / \mathrm{d}$ & 29 & 58 \\
\hline $4-5 \mathrm{~h} / \mathrm{d}$ & 19 & 38 \\
\hline$>5 \mathrm{~h} / \mathrm{d}$ & 02 & 04 \\
\hline
\end{tabular}

Multimodal treatment was offered. Among them motion (Rocking, bouncing, walking etc) $18(36 \%)$, change of diet $14(28 \%)$ were considerable satisfactory measures (Table-IV).

Table-IV: Positive response to treatment $(n=50)$

\begin{tabular}{|l|c|c|}
\hline Positive response to treatment & Patients & $\mathbf{( \% )}$ \\
\hline Motion (Rocking, bouncing, walking etc.) & 18 & 36 \\
\hline Drugs (Antihistamin, simethicone, phenobarbital) & 05 & 10 \\
\hline Change of diet & 14 & 28 \\
\hline Pacifier or water (Oral gratification) & 02 & 04 \\
\hline Warmth to abdomen & 02 & 04 \\
\hline Pressure to abdomen & 05 & 10 \\
\hline Increased caloric intake (25\% Glucose) & 01 & 02 \\
\hline Enema / Glycerine suppository & 03 & 06 \\
\hline
\end{tabular}

\section{Discussion}

The medical definition of colic is a healthy baby with periods of intense, unexplained fussing/crying lasting more than 3 hours a day, more than 3 days a week for more than 3 weeks $^{15}$. However, many doctors consider that definition, first described by Dr. Morris Wessel, to be overly narrow and would consider babies with sudden, severe, unexplained crying lasting less than 3 hours/day as having "colic" (so-called "non-Wessel's" colic) ${ }^{16}$.

In some study incidence of infantile colic affecting as many as $16 \%$ to $26 \%$ of newborn children in the first months of life $^{17}$ which was $20 \%$ in this study. The cumulative incidence rate of colic in the first 3 months of infancy was $48 \%$ in this study. This rate defined the occurrence of colic using the criteria proposed by Wessel, which are the criteria for diagnosis of colic in infants, which has gained most acceptance ${ }^{18}$. This study showing no difference regarding gender for colic presentation is in accordance with most other reports ${ }^{19}$. A birth weight of $<2500 \mathrm{~g}$ or a cranial circumference of $<35 \mathrm{~cm}$ are in one study associated with a higher risk of developing infantile colic ${ }^{20}$. This is contradictory to this 
result, where incidence is more in birth weight $\geq$ $2500 \mathrm{~g}$. Some studies showed a higher risk of firstborns getting infantile colic ${ }^{19}$ while another study, showed no increased risk. In this study the incidence was higher (68\%).

Maternal age has in different studies either no correlation with the risk of having an infant with colic or results in an increased tendency for mothers younger than 25 and older than 35 to have a greater risk $^{21}$. It does not correlate with this result. Most possible cause may be this study group, who are from military background; where many of these couples complete their family before 35 years of maternal age. In a study the incidence of colic is more in babies delivered vaginally ${ }^{19}$ which is similar to this study.

In Recife, a study showed that children fed exclusively at the maternal breast have a three times less chance of presenting colic when compared with non-breastfed children $^{22}$. Here Non-exclusive breastfed babies suffered more $(62 \%)$ than that of exclusive breastfed babies.

At first glance, a gastrointestinal (GI) theory of colic seems logical because fussy babies often: grunt/pass gas/double-up/cry after eating; have noisy stomachs; improve with tummy pressure, warmth or massage; may improve with pain medication (e.g. paregoric, also referred to as tincture of opium) However, $85-90 \%$ of colicky babies have no evidence of $\mathrm{Gl}$ abnormality ${ }^{23}$. Today, it is fairly well established that there are a variety of causes of colic symptoms, the most common of which include: stomach gas (due to poor burping), intestinal gas (pocketed in the intestinal tract), neurological overload (the overwhelmed and overstimulated baby that becomes exhausted) and even a muscular type of colic (perhaps due to muscle spasm and birth trauma).

Unclear aetiology, diffuse criteria for normal crying and no known relief-giving, safe and effective treatment make it difficult for health staff meeting parents who are seeking help for infantile colic. There are no clear management guidelines for the treatment of infantile colic and no evidence-based cures ${ }^{24}$. Complementary and alternative medicines often are advocated for infantile colic, yet there has been no synthesis of the evidence to inform current practice about their use ${ }^{25}$.
Over the past 15 years, many thousands of fussy babies have been given medicine in the belief that their colic was caused by painful acid reflux, so-called gastro-esophageal reflux disease (GERD). From 1999-2004, the use of a popular class of liquid antacid (proton pump inhibitor, or PPI) in young children increased 16 fold $^{26}$.

Simethicone, a safe, over-the-counter drug for decreasing intraluminal gas, has been promoted as an agent to decrease colicky episodes. A randomized, placebocontrolled, multicenter trial concluded that treatment with this agent produces results similar to those of placebo. Two other RCTs found no benefit for treatment with simethicone. Systematic reviews of studies using anti-cholinergic drugs in the treatment of colic found them to be more effective than placebo. The most commonly used agent is dicyclomine ${ }^{27}$. Current evidence suggests that dietary modifications may reduce colic in only a very small minority of infants $^{28}$. Change of diet shown improvement in 14 cases $(28 \%)$ in this study.

In an NIH funded pilot project by researchers at Penn State University, 80 new mothers were taught the "5S's." Breastfeeding mothers taught this method reported that their babies had significantly increased sleep (30-45 min/avg) and significantly reduced trend to obesity at 1 year of age (when combined with simple dietary advice) ${ }^{12}$. The "5 S's" approaches are:

1. Swaddling ${ }^{29}$ (safe swaddling carefully avoiding overheating, covering the head, using bulky or loose blankets $^{30}$ and allowing the hips to be flexed) ${ }^{31}$;

2. Side or stomach (holding a baby on the back is the only safe position for sleep, but it is the worst position for calming a fussy baby);

3. Shhh sound (making a strong shush sound near the baby's ear or using a CD of womb sound/white noise) ${ }^{32}$;

4. Swinging the baby with tiny jiggly movements (no more than 1" back and forth) always supporting the head and neck ${ }^{33}$;

5. Sucking (Letting the baby suckle on the breast, your clean finger or a pacifier). 
This study prooved the effectiveness of the above measures. A study on Premature Infant Pain Profile scores and crying time indicate poorer effects of expressed breast milk compared with $25 \%$ glucose during heel lancing ${ }^{34}$. In this study $01(2 \%)$ patients shown improvement with $25 \%$ glucose. Persistently fussy babies with poor weight gain, vomiting more than 5 times a day, or other significant feeding problems should be evaluated by a healthcare professional for other illnesses (e.g. urinary infection, intestinal obstruction, acid reflux $)^{35}$.

\section{Conclusion}

Babies are just getting accustomed to this world and, as they grow older, their colic will eventually subside. Their digestive systems will learn how to function well. In the first three months of life, babies are not well-equipped to calm themselves. Self-calming is a skill that develops slowly over time and at different rates in children. Infant colic is not an inconsequential disorder, it may have disastrous effects on the baby and the family. Education about how to cope with the situation and utilise extended family help as well as social services, combined with a trial of dietary modification, may be better treatment than initially trying medications for the baby.

\section{References}

1. Baildam EM, Hillier VF, Ward BS et al. Duration and pattern of crying in the first year of life. Dev Med Child Neurol 1995; 37(4):345-53.

2. Barr RG. Changing our understanding of infant colic. Arch Pediatr Adolesc Med 2002; 156(12):1172-74.

3. Levitzky S, Cooper R. Infant colic syndrome: maternal fantasies of aggression and infanticide. Clin Pediatr 2000; 39:395-400.

4. Li R, Fein SB, Chen J et al. Why Mothers Stop Breastfeeding: Mothers' Self-reported Reasons for Stopping During the First Year. Pediatrics 2008; 122(2): S69-S76.

5. Barr RG, Trent RB, Cross J. Age-related incidence curve of hospitalized Shaken Baby Syndrome cases: Convergent evidence for crying as a trigger to shaking, Child Abuse \& Neglect 2006; 30:7-16.
6. James F. Paulson, PhD; Sharnail D. Bazemore, MS. Prenatal and Postpartum Depression in Fathers and Its Association With Maternal Depression A Meta-analysis JAMA. 2010;303(19):1961-69.

7. St James-Roberts I, Halil T. Infant crying patterns in the first year: normal community and clinical findings. J Child Psychol Psychiat 1991;32:951-68.

8. Putnam P. Stop the PPI Express: They Don't Keep Babies Quiet! J Pediatrics 2009;154: 475-6.

9. Orenstein SR, et al. Multicenter, double-blind, randomized, placebo-controlled trial assessing the efficacy and safety of proton pump inhibitor Lansprazole in infants with symptoms of gastroesophageal reflux disease. J Pediatrics 2009; 154: 514-20

10. Gaffney KF, Henry LL. Identifying risk factors for postpartum tobacco use. J Nurs Scholarsh 2007; 39:126-32.

11. Colson ER, Rybin D, Smith LA et al. Trends and Factors Associated With Infant Sleeping Position, The National Infant Sleep Position Study, 1993-2007. Arch Pediatr Adolesc Med 2009; 163:1122-8.

12. Paul IM, Birch L. Pediatric Ambulatory Society (PAS) Meeting The Relationship between Infant Feeding, Sleeping and Weight Gain. Baltimore, MD May 4, 2009.

13. Taheri S, Lin L, Austin D et al. Short sleep duration is associated with reduced leptin, elevated ghrelin and increased body mass index. PLoS Med 2004 Dec; 1(3):e62. Epub 2004 Dec 7.

14. Sleep in America Poll Final Report, National Sleep Foundation, March 2004;165.

15. Wessel MA, Cobb JC, Jackson EB et al. Paroxismal fussing in infancy, sometimes called "colic." Pediatrics 1954 Nov; 14(5):421-35.

16. Barr RG, Rotman A, Yaremko J et al, The Crying of Infants With Colic: A Controlled Empirical Description. Pediatrics 1992 Jul; 90(1 Pt 1):14-21.

17. Garrison MM, Christakis DA. A Systematic Review of Treatments for Infant Colic. Pediatrics 2000; 106(1):184 -90. 
18. Clifford TJ, Campbell MK, Speechley KN et al. Infant colic: Empirical evidence of the absence of an association with source of early infant nutrition. Arch Pediatr Adolesc Med 2002; 156:1123-8.

19. Talachian E, Bidari A, Rezaie MH. Incidence and risk factors for infantile colic in Iranian infants. World J Gastroenterol 2008; 14(29):4662-6.

20. Sondergaard C, Skajaa E, Henriksen TB. Fetal growth and infantile colic. Arch Dis Child Fetal Neonatal Ed 2000; 83(1):F44-7.

21. Canivet C. Infant crying- A safety risk? Lakartidningen 2005 June $6-12 ; 102(23): 1805-07$.

22. Saavedra MAL, Juvenal S, Costa DD et al. Infantile colic incidence and associated risk factors: A cohort study. J Pediatr (Rio J) 2003; 79(2):115-22.

23. Lucassen PLBJ, Assendelft WJJ, Gubbels JW et al. Effectiveness of treatments for infantile colic: Systematic review. BMJ 1998 May 23; 316:1563-9.

24. Cohen-Silver J, Ratnapalan S. Management of infantile colic: A review. Clin Pediatr (Phila) 2009 Jan; 48(1):14-7.

25. Rachel Perry, Katherine Hunt, Edzard Ernst. Nutritional Supplements and Other Complementary Medicines for Infantile Colic: A Systematic Review; Pediatrics 2011 April; 127(4):720 -33

26. Barron JJ, Tan H, Spalding J et al. Proton pump inhibitor utilization patterns in infants. J Pediatr Gastroenterol Nutr 2007 Oct; 45(4):421-7.
27. Roberts DM, Ostapchuk M, O'Brien JG. Infantile Colic. Am Fam Physician 2004 Aug 15; 70(4):735-40.

28. JN Critch, Infantile colic: Is there a role for dietary interventions? Paediatr Child Health 2011; 16(1):47-9.

29. Van Sleuwen BE, Engelberts AC, Boere-Boonekamp MM et al. Swaddling: A systematic review. Pediatrics 2007 Oct; 120(4):e1097-1106.

30. Wolff PH. The causes, controls, and organization of behavior in the neonate. Psychol 1966; 5:1-105

31. Karp HK. Safe Swaddling and Healthy Hips: Don't Toss the Baby out With the Bathwater. Pediatrics 2008; 121:1075-76.

32. Spencer JAD, Moran DJ, Lee A et al. White noise and sleep induction. Arch Dis Child 1990, 65:135-7.

33. Gatts JD, Fernbach SA, Wallace DH et al. Reducing crying and irritability in neonates using a continuously controlled early environment. Journal of Perinatology 1995; 15:215-21.

34. Bueno M, Stevens B, de Camargo PP et al. Breast milk and glucose for pain relief in preterm infants: A noninferiority randomized controlled trial. Pediatrics 2012; 129(4):664-70.

35. Heine RG, Jordan B, Lubitz $L$ et al. Clinical predictors of pathological gastro-esophageal reflux in infants with persistent distress. J Paed Ch Health 2006; 42:134-9. 